\title{
Inhospital outcome of elderly patients in an intensive care unit in a Sub-Saharan hospital
}

\author{
M. Lankoandé ${ }^{*}$ (D), P. Bonkoungou'², A. Simporé2, G. Somda ${ }^{3}$ and R. A. F. Kabore ${ }^{4}$
}

\begin{abstract}
Background: In Burkina Faso, demographics are changing and we are seeing a growing prevalence of older patients in intensive care units. Elderly people have increased health care needs but there is a lack of geriatric specialists. This study aimed to analyze in-hospital outcome of patients aged over 65 years, admitted to the Intensive Care Unit (ICU) at Yalgado Hospital.

Methods: We carried out a 5-year retrospective study in the ICU of Yalgado Ouédraogo Hospital. Elderly patients with completed records were included. Baseline characteristics, clinical and outcome were analyzed.

Results: Two thousand one hundred sixteen patients were admitted to ICU, 237 (11.2\%) of whom were included. There were 70 females and 167 males. The median age was $71.7 \pm 6.1$ years. The overall mortality rate in ICU was $73 \%$, of whom $90 \%$ died within 7 days after admission. In multivariate analysis, shock (Odds Ratio: $O R=2.2, p=0.002$ ), severe brain trauma (OR; 9.6, $p=0.002)$, coma (OR $5.8 p<0.003)$, surgical condition $(\mathrm{OR}=4.2, p=0.003)$, ASAPS Score $\geq 8$ (OR=4. $3, p=0.001)$, complication occurring $(\mathrm{OR}=5.2, p=0.001)$ and stroke $(\mathrm{OR}=3.7, p=0.001)$ were independent factors.
\end{abstract}

Conclusion: Elderly patients were frequent in ICU and their mortality rate was high. Stroke, severe brain trauma, surgery, complications occurring during hospitalization were independent risk factors of death.

Keywords: Elderly, Intensive care unit, Mortality

\section{Background}

Elderly is defined as a chronological age equal to or above 65 years worldwide or above 60 years in Africa [1]. Worldwide, the elderly population continues to grow due to increased life expectancy [2]. In 2015, the world elderly population rose by 55 million and the proportion reached $8.5 \%$ [3]. In Africa, the proportion of elderly accounted for $6.6 \%$ in 2015 and will reach $9.6 \%$ in 2050 . This increase is also seen in Burkina Faso. In 1985, the census in Burkina Faso reported 319,496 elderly people accounting for $4 \%$ of the general population. [4] This rose to $475,812(2.4 \%)$ in 2016 [5]. Despite the increase of the number of elderly people in Burkina Faso, their proportion is reduced by the explosion of births and the youth of the population. One of the consequences of the

\footnotetext{
*Correspondence: m.hamtaani@gmail.com

${ }^{1}$ Anaesthesia Intensive Care, Regional Hospital of Koudougou, Koudougou, Burkina Faso

Full list of author information is available at the end of the article
}

growth in the number of elderly patients is the increased requirement for admission to ICU. They require appropriate healthcare facilities, and special skills and human resources. They have higher morbidity and mortality because of associated co-morbidities. In developing countries, intensive care is limited by poverty, lack of equipment, inadequate skills and insufficient human resources. This study aims to assess outcomes for elderly patients admitted to ICU in the first referral teaching hospital Yalgado Ouédraogo in Burkina Faso.

\section{Methods}

We carried out a retrospective study of elderly patients admitted to the ICU of the tertiary Hospital Yalgado Ouédraogo over a five-year period (1st January, 2011 to 31st December, 2015). Yalgado Hospital is a tertiary care, governmental hospital, with an overall capacity of 800 beds and an 8 bed ICU where patients are managed by anesthesiologists. The average number of admissions to 
ICU was about 200 patients per year with a mortality of $51.6 \%$ [6]. The ICU is poorly equipped (one transport ventilator, one defibrillator and monitors). Patients receive fluid and electrolyte management, transfusions, oxygen, vasoactive drugs, and nutrition (parenteral and oral nutrition). Non-invasive ventilation and CPAP were not used. Relevant data recorded includes socio-demographic characteristics, co-morbidities, diagnosis, indications for ICU admission, Glasgow Coma Score at admission, the Ambulatory Simplified Acute Physiologic Score (ASAPS) [7], Charlson co-morbidity score, need for mechanical ventilation, blood transfusion and or hemodialysis, sepsis, shock on admission, length of stay and outcome. The Ambulatory Simplified Acute Physiologic Score is a scale used for patients admitted to ICU to evaluate the severity of their condition.

Ethical and National Scientific Research and Technology Center (ENSRTC) approved the study. The Epidemiologic Information package version 7.1.5.0 was used for data analysis. Descriptive statistics included frequency for nominal variables and mean \pm standard deviations or medians and interquartile ranges for continuous variables according to their distribution. Independent $t$-test (continuous variables) and Chi-square test (categorical variables) were used in univariate analysis when comparing age groups, survivors to non-survival patients. A $p$ value $\leq 0.05$ was considered as significant. The total sample was divided into three groups according to age (65-74 years or « young old », 75-84 years or old old, and $>85$ years or oldest old).

\section{Results}

In total, 2116 patients were admitted to ICU of whom 237 (11.2\%) were included in our study. The mean age was $71.7 \pm 6.1$ years, with male: female ratio of 2.3. The demographic characteristics are summarized in Table 1.

Comorbidity was identified in 191 cases $(80.6 \%)$ of which $49.4 \%(n=117)$ had more than 2 comorbidities and $19.4 \%(n=46)$ had none. The Charlson median score was 4.8. A score $\geq 4$ was recorded in $89.4 \%$ at admission in ICU. Past histories of hypertension (50.6\%), diabetes (23.6\%) and peptic ulcers (6.3\%) were common. The clinical features are summarized in Table 2. 42.1\% of patients were comatose, with Glasgow coma score $<8$. 100 (49.02\%) patients had ASAPS score $\geq 8$.

Medical conditions (60\%), particularly of the Central Nervous System (CNS) (37.97\%), were the most common. Among all diseases, stroke was most frequent (27.4\%) followed by peritonitis. Care was based on fluid and electrolyte management, pain relief, and supply of oxygen. Only 2 patients were mechanically ventilated. During hospitalization, complications occurred in 89 patients $(37.55 \%)$ of which acute respiratory distress syndrome (ARDS) was the main one (10.55\%). In total 173
Table 1 Demographic characteristics of patients $(n=237)$

\begin{tabular}{|c|c|c|c|}
\hline Characteristic & Mean & Number & Percentages \\
\hline Age (years) & $71.7 \pm 6.1$ & & \\
\hline $65-74$ years & & 167 & 70.5 \\
\hline $75-84$ years & & 58 & 24.5 \\
\hline Over 84 years & & 12 & 5 \\
\hline \multicolumn{4}{|l|}{ Gender } \\
\hline Male & & 167 & 70.5 \\
\hline Female & & 70 & 29.5 \\
\hline \multicolumn{4}{|l|}{ Residency } \\
\hline Urban & & 159 & 67.1 \\
\hline Rural area & & 78 & 32.9 \\
\hline \multicolumn{4}{|l|}{ Profession } \\
\hline Retired & & 48 & 32.6 \\
\hline Housewife & & 37 & 25.2 \\
\hline Farmer & & 31 & 21.1 \\
\hline Public/Private service & & 31 & 21.1 \\
\hline \multicolumn{4}{|l|}{ Referral facilities } \\
\hline District hospital & & 107 & 45.1 \\
\hline Regional hospital & & 39 & 16.4 \\
\hline Dispensary & & 3 & 1.3 \\
\hline Teaching hospital & & 19 & 8 \\
\hline Private Hospital & & 69 & 29.1 \\
\hline
\end{tabular}

Teaching Hospital (YO: 8 cases; Blaise Compaore Hospital: 6 cases; Sourou Sanou Hospital = 5 cases);

(73\%) patients died in ICU. Table 3 summarizes the diagnoses and in-hospital outcome of patients.

The mean length of ICU stay was $5.3 \pm 7.4$ days [IC 95\%; 1-58]. Ninety percent of those that died, did so within a week while $10 \%$ died after a week. Survivors and non-survivors were comparable based on demographic data (Table 4). When comparing survivors to non-survivors, there was a significant difference related to the emergency context $(p=$ $0.001)$, surgical condition $(p=0.003)$, coma condition $(p=$ $0.001)$, shock $(p=0.002)$, Charlson score $\geq 8(p=0.03)$, ASAPS score $8 \geq$ at admission $(p=0.0001)$, stroke $(p<$ $0.0001)$, diabetic complication $(p=0.01)$, and complication in ICU $(p=0.001)$ in univariate analysis.

Most patients were between 64 to 74 years old. There was a significant difference between the age groups for Charlson score $(p=0.001)$ and complications in ICU $(p=0.01)$ (Table 5).

In multivariate analysis, surgery, coma at admission, shock, stroke, and severe brain trauma were independent risks factors of ICU death (Table 6).

\section{Discussion}

This retrospective study found that elderly patients represented $11.2 \%$ of admissions to ICU. This rate is comparable to the $(10 \%)$ of Owojuyigbe et al. [8] and the 
Table 2 Clinical characteristics of patients $(n=237)$

\begin{tabular}{|c|c|c|c|}
\hline Clinical characteristics & Mean & Number & Percentage \\
\hline \multicolumn{4}{|l|}{ Reasons of admission $(n=237)$} \\
\hline $\mathrm{ACS}^{\mathrm{a}}$ & & 133 & 56.1 \\
\hline Shock & & 78 & 32.9 \\
\hline Thermal burns & & 11 & 4.6 \\
\hline $\mathrm{ARDS}^{\mathrm{b}}$ & & 9 & 3.8 \\
\hline Poor condition & & 6 & 2.5 \\
\hline Glasgow coma score $(n=214)$ & $9.6 \pm 4.0$ & & \\
\hline$<8$ & & 90 & 42.1 \\
\hline $8-14$ & & 78 & 36.4 \\
\hline 15 & & 46 & 21.5 \\
\hline \multicolumn{4}{|l|}{ Blood Pressure $(n=237)$} \\
\hline Systolic Pressure & $132.5 \pm 36.6$ & & \\
\hline Diastolic pressure & $78.1 \pm 23.5$ & & \\
\hline Hypertension & & 124 & 52.3 \\
\hline Hypotension & & 35 & 14.7 \\
\hline Temperature $(n=237)$ & & 111 & 46.8 \\
\hline \multicolumn{4}{|l|}{ Hyperthermia } \\
\hline Hypothermia & & 9 & 3.8 \\
\hline ASAPS $(n=204)$ & $7.9 \pm 3.5$ & & \\
\hline
\end{tabular}

ASAPS Ambulatory simplified acute physiologic score

${ }^{a} A C S$ Alteration of consciousness

${ }^{\mathrm{b}}$ ARD Acute Respiratory Distress Syndrome

(16.6\%) of Belayachi et al. [9]. In developed countries elderly admissions rate to ICU was high. The rate of admission in our study may be due to life expectancy shortness that reflects Burkinabè demographic profile.

Patients mean age was $71.7 \pm 6.1$ years in our study. Other study found a mean age of 72 years in Morocco [9], 75.4 \pm 6.8 years in Brasilia [10] and 73 years in Nigeria [8]. In our study, patients were mainly males. There was no correlation between gender and admission in the literature $[8,9]$. Some studies reported similar results to ours [11, 12], but Fowler et al. [13] reported higher mortality in the female group.

Patient outcome was poor in our study with a mortality rate of $73 \%$. Belayachi et al. [9] in Morocco, Wade et al. [14] in Senegal reported 44.7 and $42.8 \%$ respectively. The high mortality reported in Africa compared to developed countries may be due to inadequate equipment, resources and care limitations [9].

Advanced age alone does not preclude successful outcome [15]. In multivariate analysis independent risk factors were surgical conditions, coma, shock during admission, ASAPS $\geq 8$, stroke, severe brain trauma. This result is comparable to literature reports $[16,17]$. In our findings, stroke was the main cause of hospitalization, followed by peritonitis. There is no difference between age groups in term of mortality. The mean length of stay
Table 3 Diagnosis and outcome of patients $(n=237)$

\begin{tabular}{|c|c|c|}
\hline Clinical data & Number & Percentage \\
\hline \multicolumn{3}{|l|}{ Admission condition } \\
\hline Medical condition & 183 & 77.2 \\
\hline Surgical condition & 54 & 22.8 \\
\hline \multicolumn{3}{|l|}{ Diseases } \\
\hline Stroke & 65 & 27.4 \\
\hline Prostate tumor & 27 & 11.4 \\
\hline Sepsis & 26 & 10.9 \\
\hline Trauma/Burn & 25 & 10.5 \\
\hline Bowel obstruction & 13 & 5.5 \\
\hline Heart disease & 18 & 2.5 \\
\hline Diabetes Acute metabolic complications & 20 & 8.4 \\
\hline Kidney failure & 16 & 6.7 \\
\hline Other ${ }^{a}$ & 27 & 11.4 \\
\hline Total & 237 & 100 \\
\hline \multicolumn{3}{|l|}{ Complications } \\
\hline Sepsis & 25 & 10.5 \\
\hline Acute Respiratory Distress Syndrome & 38 & 42.7 \\
\hline Shock & 15 & 6.3 \\
\hline Coma & 19 & 21.3 \\
\hline Bed sores & 8 & 3.4 \\
\hline Acute pulmonary edema & 5 & 2.1 \\
\hline Pulmonary aspiration & 5 & 2.1 \\
\hline Pulmonary embolism & 1 & 0.4 \\
\hline Other ${ }^{b}$ & 5 & 2.1 \\
\hline \multicolumn{3}{|l|}{ Outcomes } \\
\hline Death in ICU & 173 & 73 \\
\hline Transfer to other ward & 48 & 20.2 \\
\hline Hospital discharge with physician authorization & 10 & 4.2 \\
\hline Discharge without physician authorization & 6 & 2.5 \\
\hline Total & 237 & 100 \\
\hline
\end{tabular}

aOther: anemia ( $n=3)$, dehydratation $(n=2)$

${ }^{\mathrm{b}}$ Hernia, blood disorder, ulcer, hydronephrosis, asthma, skin disease, leukemia

in ICU was $5.3 \pm 6.8$ days. While $46.6 \%$ of patients died within the first 3 days of admission, $90 \%$ of patient died within a week. For patients over 84 years, LOS was shorter and in-hospital mortality was less than patients aged less than 84 years. This can be explained by the family taking their relative home once they understand that the outlook for recovery is bleak. This explains the relatively low mortality rate and short stay. The overall poor outcomes may be due to late consultation and poor quality of care due to the inadequate facilities, equipment and lack of medications. Delay in consultation may be related to limited education, use of traditional medicine, poverty with concern about hospital costs and poor transportation. 
Table 4 Comparison of survivors and non-survivor's patients $(n=237)$

\begin{tabular}{|c|c|c|c|c|}
\hline Characteristics & $\begin{array}{l}\text { All patients } \\
(N=237)\end{array}$ & $\begin{array}{l}\text { Non-survivors } \\
(n=173)\end{array}$ & $\begin{array}{l}\text { Survivors } \\
(n=64)\end{array}$ & $p$ value \\
\hline Age (Mean; years) & $71.7 \pm 6.1$ & $71.6 \pm 5.9$ & $72.1 \pm 6.4$ & 0.5 \\
\hline \multicolumn{5}{|l|}{ Age group (\%) } \\
\hline $65-74$ & $167(70.4)$ & $123(73.6)$ & $44(26.3)$ & 0.7 \\
\hline $75-84$ & $58(24.5)$ & $42(72.4)$ & $16(27.6)$ & 0.9 \\
\hline 85 above & $12(5.1)$ & $8(66.6)$ & $4(33.3)$ & 0.6 \\
\hline \multicolumn{5}{|l|}{ Gender } \\
\hline Male $(n=167)$ & $167(70.4)$ & $127(76.05)$ & $40(23.9)$ & 0.1 \\
\hline Female $(n=70)$ & $70(29.6)$ & $46(65.7)$ & $24(34.3)$ & \\
\hline \multicolumn{5}{|l|}{ Reference specialty (\%) } \\
\hline Emergency service & $134(56.4)$ & $108(80.6)$ & $26(20.4)$ & 0.001 \\
\hline Medicine & $21(8.8)$ & $14(66.6)$ & $7(33.8)$ & 0.4 \\
\hline Surgery & $54(22.8)$ & $49(90.7)$ & $5(9.3)$ & 0.003 \\
\hline \multicolumn{5}{|l|}{ Reasons for admission } \\
\hline ACS & $133(56.1)$ & $109(81.9)$ & $24(18)$ & $<0.001$ \\
\hline Poor condition & $6(2.5)$ & $3(50)$ & $3(50)$ & 0.3 \\
\hline Burn & $11(4.6)$ & $7(63.64)$ & $4(36.4)$ & 0.4 \\
\hline ARDS & $9(3.8)$ & $7(77.7)$ & $2(22.2)$ & 1 \\
\hline Shock & $78(32.9)$ & $47(60.3)$ & $31(39.7)$ & 0.002 \\
\hline Charlson Score (Median) & $4.8 \pm 1.8$ & $4.6 \pm 1.7$ & $5.09 \pm 2.04$ & 0.12 \\
\hline$\geq 8$ & $20(8.4)$ & $11(55)$ & $9(45)$ & 0.03 \\
\hline$<8$ & $217(91.6)$ & $103(47.4)$ & $76(52.6)$ & 0.4 \\
\hline Glasgow coma score (Mean valu) & $9.64 \pm 4.01$ & $8.9 \pm 3.8$ & $11.8 \pm 3.6$ & 0.03 \\
\hline$<8$ & 42.06 & $69(88.4)$ & $9(11.5)$ & $<0.001$ \\
\hline$\geq 8$ & 57.9 & $58(68.2)$ & $76(31.8)$ & \\
\hline ASAPS score (Mean) & $7.9 \pm 3.5$ & $8.6 \pm 3.5$ & $5.8 \pm 2.6$ & $<0.001$ \\
\hline ASAPS $\geq 8$ & & $150(87)$ & 13 & \\
\hline ASAPS $<8$ & & $109(63.5)$ & 36.6 & \\
\hline \multicolumn{5}{|l|}{ Diagnosis } \\
\hline Stroke & $65(27.4 \%)$ & $57(87.69 \%)$ & $8(12.31 \%)$ & 0.001 \\
\hline Peritonitis & $22(9.3 \%)$ & $18(81.82 \%)$ & $4(18.18 \%)$ & 0.4 \\
\hline $\mathrm{AMCD}^{\mathrm{A}}$ & $20(8.4 \%)$ & $10(50 \%)$ & $10(50 \%)$ & 0.01 \\
\hline $\mathrm{SBT}^{\mathrm{B}}$ & $19(8 \%)$ & $18(94.74 \%)$ & $1(5.26 \%)$ & 0.02 \\
\hline Bowel obstruction & $13(5.5 \%)$ & $7(53.85 \%)$ & $6(46.15 \%)$ & 0.1 \\
\hline Burn & $10(4.2 \%)$ & $6(60 \%)$ & $4(40 \%)$ & 0.4 \\
\hline Severe infection & $10(4.2 \%)$ & $8(80 \%)$ & $2(20 \%)$ & 0.7 \\
\hline Prostatic adenoma & $9(3.8 \%)$ & $5(55.56)$ & $4(44.44)$ & 0.2 \\
\hline Heart disease & $6(2.5 \%)$ & $4(66.67 \%)$ & $2(33.33 \%)$ & 0.6 \\
\hline Prostatic cancer & $5(2.1 \%)$ & $1(20 \%)$ & $4(80 \%)$ & 0.01 \\
\hline Inguinal hernia & $5(2.1 \%)$ & $3(60 \%)$ & $2(40 \%)$ & 0.6 \\
\hline Other ${ }^{c}$ & $53(22.4 \%)$ & $36(67.92 \%)$ & $17(32.08 \%)$ & 0.1 \\
\hline \multicolumn{5}{|l|}{ Complications occurred in ICU } \\
\hline Yes $=89$ & 89 (37.5\%) & 80 (89.9\%) & $9(10.1 \%)$ & $<0.001$ \\
\hline Non $=148$ & $148(62.5 \%)$ & $93(62.8 \%)$ & $55(37.2 \%)$ & \\
\hline Mechanical ventilation & $2(0.8 \%)$ & $2(100 \%)$ & 0 & $\mathrm{Ki}=0.7$ \\
\hline Length of stay in ICU (mean) & $5.3 \pm 7.4$ & $5.2 \pm 8$ & $5.5 \pm 5.1$ & 0.8 \\
\hline
\end{tabular}

ACS Alteration of consciousness, ARDS Acute Respiratory Distress Syndrom, AMCD Acute metabolic complication of diabetes, SBT Severe brain trauma ICU Intensive Care Unit, ASAPS Ambulatory Simplified Acute Physiologic Score

A Acute Metabolic Complication of Diabetes

B Severe Brain Trauuma

C Other disease 
Table 5 Comparison of patients according to age group $(n=237)$

\begin{tabular}{|c|c|c|c|c|}
\hline Variables & $\begin{array}{l}65-74 \text { years } \\
n=167(70.4 \%)\end{array}$ & $\begin{array}{l}75-84 \text { years } \\
n=58(24.5 \%)\end{array}$ & $\begin{array}{l}\text { Over } 84 \text { years } \\
n=12(5.1 \%)\end{array}$ & $p$ value \\
\hline Age (Mean; years) & $68.3 \pm 2.8$ & $78.2 \pm 2.5$ & $86.6 \pm 1.6$ & $<0.001$ \\
\hline \multicolumn{5}{|l|}{ Gender } \\
\hline Male $(n=167)$ & 118 & 40 & 9 & \multirow[t]{2}{*}{0.9} \\
\hline Female $(n=70)$ & 49 & 18 & 3 & \\
\hline \multicolumn{5}{|l|}{ Reasons for admission } \\
\hline ACS & 92 & 33 & 6 & 0.9 \\
\hline Poor condition & 68 & 26 & 5 & 0.6 \\
\hline Burn & 7 & 2 & 1 & 0.7 \\
\hline ARDS & 13 & 6 & 0 & 0.4 \\
\hline Shock & 11 & 4 & 2 & 0.4 \\
\hline Charlson Score (Median) & 4.5 & 5.1 & 6.3 & 0.001 \\
\hline$\geq 8$ & 12 & 5 & 3 & \multirow[t]{2}{*}{0.1} \\
\hline$<8$ & 155 & 53 & 9 & \\
\hline Glasgow coma score (mean) & $9.7 \pm 4.02$ & $9.4 \pm 4.1$ & $8.8 \pm 3.5$ & 0.6 \\
\hline$<8$ & 12 & 5 & 3 & \multirow[t]{2}{*}{0.1} \\
\hline$\geq 8$ & 155 & 53 & 9 & \\
\hline ASAPS score (Mean) & $7.9 \pm 3.8$ & $8.08 \pm 2.9$ & $8.1 \pm 2.7$ & 0.9 \\
\hline ASAPS $\geq 8$ & 65 & 25 & 8 & 0.1 \\
\hline ASAPS $<8$ & 77 & 22 & 4 & 0.4 \\
\hline Complications in ICU & & & & 0.01 \\
\hline Yes $=89$ & 65 & 19 & 5 & \multirow[t]{2}{*}{0.6} \\
\hline Non $=148$ & 102 & 39 & 7 & \\
\hline Mechanical ventilation & 2 & 0 & 0 & 0.6 \\
\hline Length of stay ICU (mean) & $5.3 \pm 6.8$ & $5.6 \pm 9.2$ & $2.7 \pm 2.2$ & 0.4 \\
\hline Death & $123(73.6)$ & $42(72.4)$ & $8(66.6)$ & 0.2 \\
\hline
\end{tabular}

ACS Alteration of consciousness, ARDS Acute Respiratory Distress Syndrom, AMCD, Acute metabolic complication of diabetes, SBT Severe brain trauma

Table 6 Risk factors for ICU mortality of elderly patients

\begin{tabular}{lll}
\hline Diagnosis & Adjusted OR (Cl 95\%) & $p$ \\
\hline Clinical situation & Reference & \\
Surgery & $4.2[2.4-10.3]$ & 0.003 \\
Coma at admission & $2.9[1.6-5.4]$ & 0.001 \\
Coma in ICU & $5.8[2.3-14.6]$ & \\
Shock during admission & $2.2[1.6-4.0]$ & 0.002 \\
ASAPS $\geq 8$ & $4.3[1.1-8.5]$ & 0.001 \\
Stroke & $3.7[1.6-8.7]$ & 0.001 \\
Severe brain trauma & $9.6[1.2-75.1]$ & 0.02 \\
Complications occurred in ICU & & 0.001 \\
No & Reference & \\
Yes & $5.2[2.4-11.3]$ & 0.001 \\
\hline
\end{tabular}

This study has limitations due to being retrospective. We did not assess the impact of pre-hospitalization condition. Blood test abnormalities, and the impact of APACHE and SOFA scores on outcome were not evaluated and long-term mortality after hospital discharge was not studied.

\section{Conclusion}

These results show that elderly patients in ICU have a high risk of ICU death. Risk factors include coma at admission, shock state, high ASAPS, severe brain trauma, stroke and surgical condition. We need to better equip our ICU to assess and manage carefully elderly patients in order to reduce ICU mortality. Training geriatric specialists could improve chronic disease care of older patients and reduce their admission to ICU. A prospective study could give more information on risk and long term outcome of these frail patients. 


\section{Abbreviations}

ACS: Alteration of consciousness; AMCD: Acute metabolic complication of diabetes; APACHE: Acute physiology and chronic health evaluation; ARDS: Acute respiratory distress syndrome; ASAPS: Ambulatory simplified acute physiologic score; ICU: Intensive care unit; NCSRT: National Center of Scientific Research and Technology; OR: Odd ratio; SBT: Severe brain trauma; SOFA: Sequential organ failure assessment

\section{Acknowledgements}

I would like to acknowledge, Professor Mion and Dr. Owue for English language improvement of this paper.

\section{Availability of data and materials}

The data of this study are available from the corresponding author (LANKOANDE Martin m.hamtaani@gmail.com, 15 BP 106 Ouagadougou 15).

\section{Authors' contributions}

GS, ML collected and reviewed data; ML, SG, AS contributed to conception and design, analyzed and interpreted the data. ML, PB wrote the manuscript. RAFK revised of the manuscript in terms of important or intellectual content. All authors read and approved the final manuscript.

\section{Authors' information}

- GS is a general practitioner,

- ML is a Anesthetist working at in Anesthesia and Intensive Care Unit at Regional Hospital of Koudougou,

- PB is an Assistant in Anesthesiology at the University PhD Joseph KiZerbo.

- AS is an Assistant in Anesthesiology at the University PhD Joseph KiZerbo

- RAFK, PhD, is a professor in Anesthesiology at the University PhD Joseph Ki-Zerbo.

\section{Ethics approval and consent to participate}

The Ethical and National Scientific Research and Technology Center (ENSRTC) (number 032/16) approved this study.

\section{Consent for publication}

Not applicable.

\section{Competing interests}

The authors declare that they have no competing interests.

\section{Publisher's Note}

Springer Nature remains neutral with regard to jurisdictional claims in published maps and institutional affiliations.

\section{Author details}

'Anaesthesia Intensive Care, Regional Hospital of Koudougou, Koudougou, Burkina Faso. ${ }^{2}$ Anesthesia Intensive Care, Yalgado Ouedraogo Hospital, Ouagadougou, Burkina Faso. ${ }^{3}$ Yalgado Ouedraogo Hospital, Ouagadougou, Burkina Faso. ${ }^{4}$ Anesthesia Intensive Care, Blaise Compaoré Hospital,

Ouagadougou, Burkina Faso.

Received: 21 September 2017 Accepted: 15 August 2018

Published online: 25 August 2018

\section{References}

1. Mkum. WHO _ Definition of an Older or Elderly Person. 2013 https://www.scribd. com/document/190077600/WHO-Definition-of-an-Older-or-Elderly-Person

2. Wan H, Goodkind D, Kowal P. An aging world: 2015; 2016. p. P95/16-1.

3. Aegon. 2013. The changing face of retirement: the Aegon retirement readiness survey 2013-country reports. Aegon and the Transamerica Center for Retirement Studies. Dowloaded in URL: https://www.aegon.com/ en/Home/Research/Aegon-Retirement-Readiness-Survey-2013.

4. Institut national de la statistique et de la demographie; La population du Burkina Faso de 1997 à 2006. 2009.

5. The world factbook. Africa, Burkina Faso, June 2017. URL: https://www.cia. gov/library/publications/the-world-factbook/geos/uv.html. Accessed 21 June 2017
6. Bonkoungou P, Traoré I, Bako YP, Sanou J, Ouédraogo N. La mortalité en réanimation polyvalente du centre hospitalier universitaire Yalgado Ouédraogo de Ouagadougou au Burkina-Faso. Ann Fr Anesth Reanim. 2014;33(2):A310. https://doi.org/10.1016/j.annfar.2014.07.523. https://www. sciencedirect.com/science/article/pii/S0750765814007722

7. Dia NM, et al. Interest of ambulatory simplified acute physiology score (ASAPS) applied to patients admitted in an intensive care unit of an infectious diseases unit in Dakar. PS SowBull Soc Pathol Exot. 2015;108:175-80.

8. Owojuyigbe AM, Adenekan AT, Babalola RN, Adetoye AO, Olateju SOA, Akonoghrere UO. Pattern and outcome of elderly admissions into the Intensive Care Unit (ICU) of a low resource tertiary hospital. East Cent Afr J Surg. 2016;21(2):40. ISSN 2073-9990

9. Jihane B, El khayari M, Dendane T, Madani N, Abidi K, Abouqal R, Zeggwagh AA. Factors predicting mortality in elderly patients admitted to a Moroccan medical intensive care unit. S Afr J Crit Care. 2012;28(1):22-7. https://doi.org/ 10.7196/SAJCC.122.

10. de Cristo Stein F, Barros RK, Feitosa FS, Toledo DO, da Silva JM Jr, Ísola AM, Rezende E. Prognostic factors in elderly patients admitted in the intensive care unit. Rev Bras Ter Intensiva. 2009;21(3):255-61.

11. Williams TA, Dobb GJ, Finn JC, Webb SA. Long-term survival from intensive care: a review. Intensive Care Med. 2005;31(10):1306-15.

12. Friedrich JO, Wilson $\mathrm{G}$, Chant C. Long-term outcomes and clinical predictors of hospital mortality in very long stay intensive care unit patients: a cohort study. Crit Care. 2006;10(2):R59.

13. Fowler RA, Sabur N, Li P, Juurlink DN, Pinto R, Hladunewich MA, et al. Sexand age-based differences in the delivery and outcomes of critical care. Can Med Assoc J. 2007;177(12):1513-9.

14. Wade K, Diaby A, Niang E, Diallo A, Diatta B. Outcome of elderly patients in an intensive care unit in Dakar, Senegal. Méd Santé Trop. 2011;22(2):223-4.

15. De Rooij SE, Govers A, Korevaar JC, Abu-Hanna A, Levi M, de Jonge E. Shortterm and long-term mortality in very elderly patients admitted to an intensive care unit. Intensive Care Med. 2006;32:1039-44.

16. Lerolle N, Trinquart L, Bornstain C, Tadié J-M, Imbert A, Diehl J-L, et al. Increased intensity of treatment and decreased mortality in elderly patients in an intensive care unit over a decade*. Crit Care Med. 2010;38(1):59-64.

17. Tabah A, Philippart F, Timsit JF, Willems V, Français A, Leplège A, et al. Quality of life in patients aged 80 or over after ICU discharge. Crit Care. 2010;14(1):R2.

\section{Ready to submit your research? Choose BMC and benefit from:}

- fast, convenient online submission

- thorough peer review by experienced researchers in your field

- rapid publication on acceptance

- support for research data, including large and complex data types

- gold Open Access which fosters wider collaboration and increased citations

- maximum visibility for your research: over $100 \mathrm{M}$ website views per year

At $\mathrm{BMC}$, research is always in progress.

Learn more biomedcentral.com/submission 